\title{
Sensorineural objective tests in the assessment of hand-arm vibration syndrome
}

\author{
Kenneth L McGeoch, W Harper Gilmour, William Taylor
}

\begin{abstract}
Assessment (staging) of workers exposed to vibration, based solely on a subjective history, has been shown to be unsatisfactory. The internationally agreed use of a sensorineural component in the Stockholm classification requires the use of sensory objective tests. Four hundred and twenty two subjects were assessed by a subjective history supplemented by multiple objective tests. These tests covered the vascular, sensorineural, musculoskeletal and dexterity aspects of hand-arm vibration syndrome. Tests to help with the differential diagnosis were also performed. Sensorineural tests are reported as are the associations between the subject's final Stockholm sensorineural staging and the subject's aesthesiometry, temperature threshold results, and grip strength. Scoring systems for these tests were evolved. Data showed that multiple sensory tests increased the accuracy of staging. Aesthesiometry, the temperature neutral zone tests, and grip strength were appropriate for the assessment of the sensory component, especially in separating sensorineural stages 0 and 1 from sensorineural stages 2 and 3 . This is an important separation for an occupational physician monitoring subjects exposed to vibration. Analyses of the sensory tests clearly indicated that they need to be done on all digits. In this survey the sensorineural damage was greatest in the forefinger (second) and the little (fifth) fingers. No association was found between smoking and the final staging, aesthesiometry, temperature neutral zone thresholds, or grip strength.
\end{abstract}

HAVS Test Centre, Babcock Energy, Renfrew

K L McGeoch

Department of Public Health, University of Glasgow W H Gilmou

Department of Occupational Medicine, University of Dundee

W Taylor (Emeritus Professor)

Requests for reprints to: K L McGeoch, HAVS Test Centre, Babcock Energy, Porterfield Road, Renfrew PA4 8DJ, Scotland.

Accepted 22 February 1993
(Occup Environ Med 1994;51:57-61)

As future legislation is likely to include monitoring of workers exposed to vibration, standardisation of objective tests requires urgent attention.

Raynaud's phenomenon of occupational origin was prescribed under the National Insurance (Industrial Injuries) Act in 1985. This prescription applies only to the vascular problems. In the past decade neurological disorders after hand-arm vibration exposure have been recognised and the name HandArm Vibration Syndrome (HAVS) is accepted internationally. Because of these developments the Working Party of the Faculty of Occupational Medicine of the Royal College of Physicians ${ }^{1}$ has recommended that the Stockholm classification ${ }^{2}$ should replace the Taylor/Pelmear classification. The neurological symptoms of HAVS include tingling and numbness at times other than during and immediately after vibratory tool use, the signs of loss of sensation, poor finger co-ordination, and an inability to do fine work.

Vibration in the finger stimulates four types of mechanoreceptive units. ${ }^{3}$ The slow adapting units are type 1 Merkel's discs and type 11 Ruffini end organs. The fast adapting units are type 1 Meissner corpuscles and type 11 Pacinian corpuscles. The sensation of touch, two point recognition, vibration, joint position, and motion are transmitted through the large myelinated A fibres. Fast adapting unit type 1 signal frequencies are $5-60 \mathrm{~Hz}$ and fast adapting unit type 11 signals are $50-400 \mathrm{~Hz}$. Also there are cold receptors, warm receptors, cold pain receptors and warm pain receptors. These are the nerve endings for A- $\delta$ and $C$ nerve fibres. ${ }^{4}$

To arrive at a sensorineural staging in the Stockholm classification it is necessary to be able to show the loss of sensory perception. We attempt to assess the ability of aesthesiometry (AESTH) and the measurement of temperature neutral zone thresholds (TNZ) to show the damage to these end organs and nerve pathways. A scoring system has been devised to evaluate these tests. Grip strength (GRIP) was measured and compared with AESTH and TNZ. To reach a Stockholm sensorineural staging it is necessary to have: (1) a detailed occupational history; (2) a detailed medical history; (3) evidence of the extent of damage to the sensorineural system; (4) a differential diagnosis to exclude other diseases; (5) an estimation of occupational and non-occupational vibration dosage, which requires both acceleration levels and exposure time.

Table 1 shows the Stockholm sensorineural classification. ${ }^{2}$

Table 1 The Stockholm sensorineural classification

Stage * Symptoms

OSN Exposed to vibration but no symptoms

1SN Intermittent numbness with or without tingling

2SN Intermittent or persistent numbness, reduced sensory perception

3SN Intermittent or persistent numbness, reduced tactile discrimination and/or manipulative dexterity

^The sensorineural stage is to be established for each hand. 


\section{Subjects and methods} SUBJECTS

Data were available for 490 men, most from heavy industry. There were two populations: (1) the Babcock Energy workforce and (2) compensation cases. Pneumatic chippers and grinders were the most common tools used by both populations. Rock drills, jack hammers, and chain saws were used by some workers in the compensation group. Of these 490 men, 68 were excluded, 47 for medical reasons (mainly cardiovascular disease), and 21 because of carpal tunnel syndrome, leaving 422 men for analyses. Of these, 225 subjects were Babcock workers and 197 were compensation cases. In $22(5 \%)$ men there was evidence of Dupuytren's contracture. They were not excluded. Table 2 shows the data by age and trade.

The mean (SD) age of the Babcock workers was $43.3(11.3)$ years, of the compensation cases $49.6(12.0)$ years, and combined $46 \cdot 1(12 \cdot 0)$ years. The average years of tool use was, for the Babcock workers 23.7 (range 2-48) years, for the compensation cases $23.9(2-47)$ years, and for the combined groups $23 \cdot 8(2-48)$ years.

\section{METHODS}

Assessment and staging by questionnaire alone without the use of objective tests has been shown to be unreliable. ${ }^{56}$ No single test will identify the various end organs and nerve fibres, nor reliably assess the sensorineural damage. Therefore the use of multiple tests has been recommended. ${ }^{7-9}$ The sensorineural tests in this survey included light touch, AESTH and measurement of the TNZ, together with thermal pain thresholds. Grip strength was recorded. Tactile discrimination and dexterity were assessed by coin and object recognition tests plus a modified Moberg pick up test. ${ }^{10}$ Adson (thoracic outlet), Tinel, and Phalen (carpal tunnel) tests were performed to help with the differential diagnosis.

All subjects had been free of vibration for at least 16 hours, had finger temperatures of at least $28^{\circ} \mathrm{C}$, and were in an environmental temperature of at least $21^{\circ} \mathrm{C}\left(70^{\circ} \mathrm{F}\right)$ for not less than 30 minutes before the tests.

Aesthesiometry was performed with an aesthesiometer developed by Renfrew ${ }^{1112}$ and modified by Carlson et al ${ }^{13}$ with their type C block for two point discrimination. The manner of performing the test was similar to that described by Carlson et al except that the aes-

Table 2 Numbers of participating subjects on age groups

\begin{tabular}{lrrrrrr}
\hline \multicolumn{7}{c}{ Age $(y)$} \\
\cline { 2 - 7 } Trade & \multicolumn{1}{l}{ <35 } & $35-44$ & $45-54$ & $55-64$ & $65+$ & Total \\
\hline Welders & 50 & 36 & 29 & 20 & 2 & 137 \\
Caulkers & 7 & 7 & 15 & 12 & 3 & 44 \\
Platers & 14 & 24 & 20 & 14 & 1 & 73 \\
Fitters & 9 & 14 & 24 & 17 & 0 & 64 \\
Other & 13 & 17 & 25 & 31 & 18 & 104 \\
Total & 93 & 98 & 113 & 94 & 24 & 422 \\
\hline
\end{tabular}

thesiometer was enclosed so that the subject could see that he was applying the correct finger pressure but could not see the test block. The normal values published by Carlson et al were accepted although some of normal controls were examined to support the data. The mean value of three pulls for each finger on both hands was recorded. In an attempt to grade the results the following scoring system was used-a mean value of $<6 \mathrm{~cm}$ was adjudged to be within the normal range and scored 0 . A mean value of between $6 \mathrm{~cm}$ and $<8 \mathrm{~cm}$ scored 1 . A mean value between $8 \mathrm{~cm}$ and $<12 \mathrm{~cm}$ scored 2 . Fingers with a mean of $\geqslant 12 \mathrm{~cm}$ scored 3 . The maximum score for a finger was 3 and for a hand 12. Temperature neutral zone thresholds were measured with the equipment (Thermotest, Sonemedic) described by Ekenvall et al. ${ }^{14}$ Changes in the test procedure were made. The pulse method as described by Swerup and Nilsson ${ }^{15}$ rather than the Marstock method was used. This entails several applications of cold stimuli to establish the cold threshold before measuring the warm threshold by several applications of warm stimuli. In the Marstock method the stimuli are used alternately. The rate of temperature change was $1^{\circ} \mathrm{C} / \mathrm{s}$. The flexor surface of the distal phalange of each finger was tested. The TNZ is the difference between the warm and cold thresholds. A zone of $10^{\circ} \mathrm{C}$ or less was accepted as normal and scored 0 . Zones of $>10^{\circ} \mathrm{C}$ to $15^{\circ} \mathrm{C}$ scored 1 and $>15^{\circ} \mathrm{C}$ scored 2 . From our normal group $10^{\circ} \mathrm{C}$ was the mean value of the neutral zone $+2 \mathrm{SD}$ and was similar to the figure published by Ekenvall et al. The thermal pain threshold was also measured for each finger. An upper limit of $49^{\circ} \mathrm{C}$ was taken as normal. Any finger with a higher pain threshold scored 1 . This gave a maximum finger score of 3 and hand score of 12 .

Grip strength was measured with a dynanometer and recorded in $\mathrm{kg}$. Initially a score was awarded for abnormal light touch sensation but this test was rarely found to be positive even when the AESTH and TNZ tests were grossly abnormal. The pain sensation test was discarded. The only sterile instruments available were cutting needles that had a definite tendency to draw blood. The test was rarely positive. In view of the HIV situation it was decided that this test was unacceptable.

\section{Results}

The relation between the diagnostic tests (AESTH, TNZ, and GRIP) and sensorineurol staging has not been expressed in terms of sensitivity and specificity in this paper. There is a complete lack of published evidence setting a gold standard for objective test results in relation to the Stockholm sensorineurol classification. The determination of sensitivity and specificity is only possible if there is some independent method of defining the disorder, in this case, the sensorineurol staging. There is a further problem with determining specificity-namely, evidence of pre-clinical objec- 
tive test findings in exposed men who do not report symptoms. ${ }^{1617}$ It is, in our view, impossible to separate these results from any false positives.

Overall $94.5 \%$ of the men were in the same Stockholm sensorineurol stage for both hands. Only one of the 422 men had hands that differed by more than one stage; $94 \%$ were right handed. As analysis of the results for "handedness" did not show any association with the Stockholm sensorineurol classification, AESTH results, TNZ results, or GRIP, handedness was not used in any further analysis. The relation between the left and right hands for the AESTH test, the TNZ test, and GRIP test was also investigated. For the AESTH test $18 \cdot 7 \%$ of the men had hand scores (on the scale of $0-12$ ) that differed by more than 2 and, only $3.6 \%$ had hand scores that differed by more than 4 . For the TNZ test $19 \cdot 5 \%$ of men had hand scores (on the 0-12 scale) that differed by more than 2 and only $6.4 \%$ had hand scores that differed by more than 4 . For the GRIP test, the right hand tended to be stronger than the left (mean difference $=5 \cdot 2$ units) but the correlation between right and left hands was high. $(r=0.85)$ In view of the similarity in the results between the left and right hands the remaining analyses have been presented only for the right hand.

With regard to smoking $39.6 \%$ of the men were current smokers. Analysis of the results for smoking did not show any association with the Stockholm sensorineural classification, AESTH results, TNZ results, or GRIP. Table 3 shows the results of univariate analysis, for the right hand, relating AESTH, TNZ, GRIP, and age to the Stockholm sensorineural stage.

For each of the numerical values a one way analysis of variance was carried out to compare the mean value across four Stockholm sensorineural stages. For the AESTH and TNZ tests there was a highly significant increase $(p<0.001)$ in the mean score (on a $0-12$ scale) from stage 0 to stage 3 . For the GRIP test, there was a highly significant decrease $(p<0.001)$ in the mean from stage 0 to stage 3. For age, there was a highly significant increase $(p<0.001)$ in the mean from stage 0 to stage 3 . Thus all four variables in table 3 were significantly associated with the Stockholm sensorineural stage.

To decide which is the most important explanatory variable for the Stockholm sensorineural stage and to determine whether two or more of the tests together would be better than any one of the tests on its own, a stepwise logistic regression was used. ${ }^{18}$ To use this method, the Stockholm sensorineural scale was condensed into two categories by combining stages 0 and 1 and stages 2 and 3 . The justification for this is that for stage 2 and stage 3 of the Stockholm sensorineural classification there should be evidence of loss of sensory perception. This separation into stages 0 and 1 and stages 2 and 3 is important, as men with stage 2 or 3 HAVS may be advised that they should not be exposed to further vibration with all the implications of this advice regarding future employment. ${ }^{19}$ It is also important in that there is no published evidence of reversibility of the neurological component of HAVS. For these reasons the analyses of the results of stages 2 and 3 are of special importance in the monitoring of a workforce exposed to vibration.

In logistic regression, if $\mathrm{p}$ denotes the probability of a man's right hand being in Stockholm sensorineural stage 2 or 3 , the model is

where $\mathrm{X}_{1}, \ldots, \mathrm{X}_{\mathrm{n}}$ denote the explanatory vari-

$$
\log _{e}\left(\frac{p}{1-p}\right)=a+b_{1} x_{1}+\ldots+b_{n} x_{n}
$$

ables (for example, AESTH) and the regression coefficients are estimated by a computer program such as the BMDP program PLR. ${ }^{20}$ In stepwise logistic regression the explanatory variable that is most strongly related to Stockholm sensorineural stage is entered into the model first and explanatory variables continue to be added until no further significant improvement in discrimination between Stockholm sensorineural stages is obtained.

In the logistic regression, AESTH, TNZ, and GRIP were entered into the model (in that order). Age did not provide any significant additional improvement in discrimination and was not included. The model obtained was

$$
\begin{gathered}
\log _{e}\left(\frac{p}{1-p}\right)=-1.94+0.38 \text { AESTH }+ \\
0.38 \mathrm{TNZ}+0.055 \text { GRIP }
\end{gathered}
$$

The contribution of each of these three explanatory variables to the regression is highly significant $(p<0.001)$ indicating that each test is useful in addition to the other two in discriminating Stockholm sensorineural stages 0 and 1 from stages 2 and 3 .

To find which of the three variables is of greatest importance in the discrimination, the values of the coefficients of each variable in the above model have been multiplied by the SD of the variable to give standardised coeffi-

\begin{tabular}{|c|c|c|c|c|c|}
\hline & \multicolumn{4}{|c|}{ Stockholm sensorineural stage } & \multirow[b]{2}{*}{$P$ Value } \\
\hline & $0(n=113)$ & $1(n=164)$ & $2(n=107)$ & $3(n=38)$ & \\
\hline $\begin{array}{l}\text { Aesthesiometry } \\
\text { Temperature thresholds } \\
\text { Grip strength } \\
\text { Age }\end{array}$ & $\begin{array}{c}2.08(2 \cdot 65) \\
2.06(2 \cdot 47) \\
42 \cdot 26(8 \cdot 55) \\
36.98(11 \cdot 28)\end{array}$ & $\begin{array}{c}3 \cdot 14(2 \cdot 76) \\
2 \cdot 16(2 \cdot 19) \\
36 \cdot 88(10 \cdot 54) \\
44 \cdot 07(11 \cdot 37)\end{array}$ & $\begin{array}{c}6 \cdot 63(2 \cdot 89) \\
5 \cdot 16(2 \cdot 75) \\
32 \cdot 26(11 \cdot 08) \\
49 \cdot 61(10 \cdot 21)\end{array}$ & $\begin{array}{c}7.97(2 \cdot 93) \\
6 \cdot 14(3.23) \\
26 \cdot 07(11 \cdot 88) \\
50 \cdot 53(10 \cdot 23)\end{array}$ & $\begin{array}{l}<0.001 \\
<0.001 \\
<0.001 \\
<0.001\end{array}$ \\
\hline
\end{tabular}
cients, which can be directly compared.

Table 3 Results (mean (SD)) of univariate analysis for the right hand 
These standardised coefficients are: for AESTH 1.30; for TNZ 1.13; for GRIP 0.62. This suggests the AESTH and TNZ are of similar importance and both are of greater importance than GRIP.

The logistic regression model can now be used to compute the probability of being in Stockholm sensorineural stages 2 or 3 for a man with any given value of AESTH, TNZ, and GRIP. Alternatively, and more simply, it can be used to compute a risk score $R$, where

$$
\begin{gathered}
\mathrm{R}=0.38 \mathrm{AESTH}+0.38 \mathrm{TNZ}+0.055 \\
\text { GRIP. }
\end{gathered}
$$

Table 4 gives the results computed for all 419 men in the survey who had all of the AESTH, TNZ, and GRIP tests recorded. The results are presented in quintiles of risk score.

Thus the percentage of men in stages 2 or 3 increased from $6 \%$ in the lowest quintile of $\mathrm{R}$ to $81 \%$ in the highest quintile. Also, in the top $5 \%$ of $R$ values $(R>0.814)$ there were 22 men of whom 21 (91\%) were in stages 2 or 3 .

The combination of the two groups of men, the Babcock men and the compensation cases, in the survey gave a wide spread of men in all the Stockholm sensorineural stages. This allowed the separation of stages 0 and 1 from stages 2 and 3 to be investigated.

As expected, it confirmed that a man from the compensation group was more likely to be in the Stockholm stage 2 or 3 than a man from the Babcock group.

The scoring of individual fingers with the AESTH test and the TNZ test was examined. The left and right hands were again similar. All the fingers were not damaged equally, however. In this population the forefingers and little fingers were more likely to have the highest scores (table 5).

\section{Discussion}

The Taylor-Pelmear classification served well for many years. As the importance of the sensorineural element became more evident and as the present evidence points to the vascular and sensorineural elements developing independently, a revision was necessary. The sep-

Table 4 Relation between risk score $(R)$ and Stockholm sensorineural stage for right hand

\begin{tabular}{lll}
\hline$R$ & No of men & $\begin{array}{l}\text { No (\%) of men in } \\
\text { Stockholm stage } 2 \text { or } 3\end{array}$ \\
\hline$<0.297$ & 81 & $5(6 \%)$ \\
$0 \cdot 297-0.385$ & 86 & $6(7 \%)$ \\
$0.386-0.509$ & 83 & $25(30 \%)$ \\
$0.510-0.649$ & 84 & $37(44 \%)$ \\
$>0.649$ & 85 & $69(81 \%)$ \\
\hline
\end{tabular}

Table 5 Percentage of tests in which one finger scored higher than the other fingers

\begin{tabular}{lllll}
\hline & Forefinger & Middle & Ring & Little \\
\hline Aesthesiometry & $20 \%$ & $5 \%$ & $7 \%$ & $20 \%$ \\
Thermal neutral zones & $17 \%$ & $7 \%$ & $11 \%$ & $26 \%$ \\
\hline
\end{tabular}

aration into two components in the Stockholm classification has been found to be of definite practical value in the monitoring of a population exposed to vibration. In 1989 the National Institute for Occupational Safety and Health recommended that: "Workers who developed stage 2 HAVS should be removed from vibration until free from symptoms." 21 In the United Kingdom the Working Party of the Faculty of Occupational Medicine recommends that: "Workers who reach either Stages 2 vascular or 2 neurological of the Stockholm scales should be advised to change employment. On reaching Stage 3 on either scale workers MUST seek redeployment." 19 It is no longer sufficient to rely on subjective history alone as the basis for such advice. Accurate assessment is necessary and becomes of great importance to a worker whose livelihood may be threatened. Furthermore there is always the possibility that litigation may follow when an employee has to change occupations.

As yet there is no single test that can show the damage to the various end organs and nerve fibres of the digits. Nor can a single test reliably stage the sensorineural element. To overcome these problems several researchers have recommended the use of multiple tests. In this HAVS centre the combination of detailed occupational and medical history combined with the results of multiple tests has led to more confidence in the accuracy of assessment of the final staging. The use of a scoring system is an attempt to define the extent of damage to the sensorineural system. It also allows for monitoring of future changes should vibration exposure continue, change, or cease.

The frequency and extent of the sensorineural changes in the little finger was an unexpected finding. The results suggest that previous surveys reported on one digit may lead to erroneous conclusions. If all fingers are not to be examined then it is evident from this survey that the forefinger and little finger were most likely to have the maximum damage for the work processes in this survey.

A number of the workers exposed to vibration were symptom free but gave positive scores with one or more of the tests. These might be false positives. Another explanation is that these are preclinical findings. A longitudinal study will show if these are, in fact, early measures of the disease. This has been suggested with regard to vibrotactile thresholds. ${ }^{17}$

Due to restrictions in examination time there is a limit to the number of objective tests that can be performed in the course of a single medical examination. Our evidence, however, suggests that the more tests performed the more reliable the staging.

Measurement of the vibrotactile thresholds has now been added to the sensorineural tests performed in this centre. A future report will incorporate vibrometry measurements. The goal must be to find the simplest, most cost effective combination of tests compatible with accurate staging. 


\section{Conclusions}

(1) For the accurate assessment (staging) and the differential diagnosis of the sensorineural component of HAVS, the use of multiple sensorineural tests requiring special instrumentation has been justified.

(2) Aesthesiometry, TNZ thresholds, and GRIP were found to distinguish stages 0 and 1 from stages 2 and 3, individually but preferably in combination.

(3) For the tools used by the subjects in this survey analyses of the data from AESTH and TNZ showed that examination of one digit may lead to erroneous conclusions. For the work processes involved in this survey, the importance of examining the second (forefinger) and the fifth (little) finger, if all digits are not to be tested, is stressed.

(4) In keeping with the recommendation of the Working Party of the Faculty of Occupational Medicine for medical monitoring of vibration exposed populations, the association between the results of the sensory tests described here and the final staging supports the use of multiple tests for routine monitoring and for the prevention of the development of advanced cases. In our view the initial expenditure on instrumentation has been fully justified.

We are greatly indebted to the Directors of Babcock Energy, Renfrew, Scotland and their safety, personnel and engineering departments for their support. Our thanks are also due to the staff of the medical department of Babcock Energy.

1 Working Party to the Faculty of Occupational Medicine of the Royal College of Physicians Report part 1. Handthe Royal College of Physicians Report part
transmitted vibration. London: RCP, 1993, 26.

2 Brammer AJ, Taylor W, Lundborg G. Sensorineural stages of the hand-arm vibration syndrome. Scand $\mathcal{F}$ Work Environ Health 1987;13:279-83.
3 Lundstrom RJI. Responses of mechanoreceptive afferent units in the glabrous skin of the human hand to vibration. Scand f Work Environ Health 1986;12:413-6.

4 Mountcastle VB, Central nervous mechanisms in mechanoreceptive disorders. American Physiological mechanoreceptive diso
Society 1984;1:789-878.

5 Olsen N. Diagnostic tests in Raynaud's phenomena in workers exposed to vibration: a comparative study. $\mathrm{Br} \mathcal{F}$ Ind Med 1988;45:426-30.

6 Pelmear P. Laboratory tests for the evaluation of HAVS. In: Proceedings of the 6th international conference on handarm vibration. Bonn; 1992 (in press).

7 Taylor W, Ogston SA, Brammer AJ. A clinical assessment of seventy eight cases of hand-arm vibration syndrome. Scand $f$ Work Environ Health 1986;265-268.

8 Harada N. Esthesiometry, nail compression and other function tests used in Japan for evaluating the hand-arm vibration syndrome. Scand $\mathcal{F}$ Work Environ Health 1987; 13: $330-3$

9 Wasserman DE, Taylor W. Historical perspectives in occupational medicine. Lessons from hand-arm vibraoccupational medicine. Lessons from hand-arm vibra-
tion syndrome research. Am f Ind Med 1991;19:539-46.

tion syndrome research. Am f Ind Med 1991;19:539-46.
10 Dellon AL. Evaluation of sensibility and re-education in the hand. Baltimore; Williams and Wilkins, 1981 .

11 Renfrew S. Aesthesiometers. Lancet 1960;1:1011.

12 Renfrew S. Fingertip sensation. A routine neurological test. Lancet 1969;1:396-7.

13 Carlson WS, Samueloff S, Taylor W, Wasserman D. Instrumentation for measurement of sensory loss in the fingertips. F Occup Med 1979;21:260-4.

14 Ekenvall L, Nilsson BY, Gustavson P. Temperature and vibration thresholds in vibration syndrome. $\mathrm{Br} \mathcal{F}$ Ind Med 1986;43:825-9.

15 Swerup C, Nilsson BY. Dependence of thermal thresholds in man on the rate of temperature change. Acta Physiol Scand 1987;131:623-4.

16 Cherniack MG, Letz $R$, Gerr F, Brammer A, Pace $P$. Detailed clinical assessment of neurological function in symptomatic shipyard workers. $B r f$ Ind Med 1986;43: 825-9.

17 Bovenzi $M$. Finger systolic pressure during local cooling: reference values in Raynaud's phenomenon of occupational origin. Int Arch Occup Environ Health 1988;61 179-81.

18 Altman DG. Practical statistics for medical research. London Chapman and Hall, 1991:351-8.

19 Working Party to Faculty of Occupational Medicine of the Royal College of Physicians Report part 1. Hand-transmitted vibration. London: RCP, 1993, 26.

20 Dixon WJ, Brown MB, eds. BMDP Statistical software. Berkeley: University of California Press, 1985.

21 DHHS. Criteria document for a recommended standard; occupational exposure to hand-arm vibration. US Department of Health and Human Services, National Institute for Occupational Safety and Health. Institute for Occupational Safety and Health. No 89-106.)

\section{NOTICE}

A course on Occupational Asthma in Practice (organiser Dr K Venables) will be held at the National Heart and Lung Institute, Dovehouse Street, London SW3 6LY on 1-2 February 1994.

Enquiries to 071-351 8172 (24 hour answering service) or fax 071-376 3442 . 